\title{
AS TECNOLOGIAS DIGITAIS NA EDUCAÇÃO À LUZ DA QUESTÃO DA TÉCNICA EM HEIDEGGER
}

\author{
Adão Caron Cambraia* \\ Paulo Evaldo Fensterseifer*
}

\begin{abstract}
Resumo
O artigo apresenta alguns aspectos acerca da questão da técnica em Heidegger e faz um exercício de aproximação com as tecnologias digitais na educação. Essa reflexão objetiva fazer uma atualização do pensamento do filósofo, que demonstra uma crescente necessidade de domínio e usos sem reflexão da tecnologia na vida e nas escolas. Foi elaborado a partir de Heidegger e Arendt e da pesquisa bibliográfica de autores como: Shery Turkle, Giovanni Sartori e Francisco Rudiger. Apontamos para a necessidade de questionar a técnica para chegarmos a essência da técnica e construirmos um caminho de liberdade do pensamento, ou seja, uma outra relação com esse fenômeno.
\end{abstract}

Palavras-chave: Linguagem. Tradição. Técnica. Educação.

\begin{abstract}
The article presents some aspects concerning the question of Heidegger and technique in doing an exercise approach with digital technologies in education. This reflection objectives an upgrade from the philosophic thinking, which demonstrates a growing need for domain and uses without reflection on life and technology in schools. It was elaborated from Heidegger and Arendt and the literature of authors as: Shery Turkle, Giovanni Sartori, Paulo Schneider and Francisco Rudiger. We pointed to the need to question the technique to get the essence of the technique and build a path of freedom of thought, i.e., a different relationship with this phenomenon.
\end{abstract}

Key words: Language. Tradition. Technique. Education.

\section{INTRODUÇÃO}

No livro intitulado "Alone Together”, Shery Turkle narra a experiência de uma mãe a procura de uma babá para sua filha. Ela entrevistava as candidatas em suas

\footnotetext{
* Doutorado em Ciências nas Educação e Professor do Instituto Federal de Educação, Ciência e Tecnologia Farroupilha. E-mail: adao.cambraia@iffarroupilha.edu.br. CV: http://lattes.cnpq.br/4507314509079204.

* Doutor em Educação pela UNICAMP, professor do programa de Pós Graduação em Educação nas Ciências (Mestrado e Doutorado); Professor do Departamento de Humanidades e Educação da Universidade Regional do Noroeste do Estado do Rio Grande do Sul - Unijuí. CV: http://lattes.cnpq.br/0895374096983586
}

DIALEKTIKÉ, v. 1, novembro 2014, p. 17-28

Artigo submetido em agosto/2014 e aceito em outubro/2014 
residências, para conhecê-las no ambiente onde vivem. Ao chegar na casa de Ronnie, uma das candidatas ao emprego, é recebida por uma pessoa que divide a moradia com ela. Logo lhe chama a atenção que a moça tem esparadrapos e talas nos dedos e, mesmo assim, não para de teclar em seu telefone celular - como demonstração de preocupação afirma que imagina ser dolorido e a moça simplesmente dá de ombros e diz que ainda consegue digitar. Informada que Ronnie está no quarto, solicita que a moça bata na porta e a chame. A moça responde: "Oh não. Eu nunca faria isso. Isso seria intrusivo. Enviarei uma mensagem para ela." (TURKLE, 2011: 2, tradução nossa). Então, ela enviou uma mensagem para Ronnie que estava ali bem próxima. Trata-se de um exemplo de como a técnica é incorporada em nossas vidas. Simplesmente pela novidade, a tornamos indispensável mesmo quando não existe necessidade em empregála.

Em algumas situações, na escola não é diferente. Ao questionarmos um professor do porquê usar determinada tecnologia, a impressão que fica, na maioria das vezes, é que se trata de um uso sem sentido para a educação, pois as justificativas, quase sempre, não são permeadas pela reflexão. Farias e Dias (2013) ao analisar discursos sobre o uso das Tecnologias Digitais (TD) na educação em documentos iberoamericanos percebem que é

Frequente observar nos textos um discurso que divulga uma ideia da potencialidade das tecnologias de informação e comunicação e sua influência direta na melhoria de qualidade na educação e no preparo do aluno para o mundo do trabalho na "era da informação". Contudo, os próprios textos assinalam a inexistência de dados que possam dar conta das experiências desenvolvidas com as TIC. (FARIAS e DIAS, 2013: 100)

Assim, essas tecnologias são anunciadas como sinônimo de melhoria da qualidade da educação e predomina um discurso que lhes atribui características instrumentais, que trará dinâmicas mais atrativas para a sala de aula. Esses discursos são reproduzidos na escola. Conforme Cambraia (2013) são discursos que pregam o domínio da informática, ao: induzir uma associação entre educação e entretenimento, ao invés da ludicidade; afirmar que com o uso das TD não importa o número de alunos em sala de aula; vincular o contato com a tecnologia ao acesso ao mercado de trabalho; estabelecer formas de controle que excluem a interdisciplinaridade existente na hipertextualidade.

DIALEKTIKÉ, v. 1, novembro 2014, p. 17-28

Artigo submetido em agosto/2014 e aceito em outubro/2014 
Frequentemente, esse discurso aliado a inúmeras "capacitações tecnológicas" de professores é utilizado para multiplicar o uso desses artefatos. Diante disso, na escola parece que se quer fazer tudo diferente do que já fizemos, com a esperança de que será diferente e melhor. Acabamos reificando o ser e passamos a ideia de que domínio de determinadas tecnologias, como um passe de mágica, resolverão uma série de problemas da educação.

Mas, a técnica não se reduz apenas aos artefatos tecnológicos. Mesmo que a neguemos estamos amarrados à técnica. Nem mesmo, a refundação de um movimento Ludista $^{1}$ a eliminaria de nossas vidas. Para Heidegger, ela seria a consumação da metafisica, um esquecimento do ser, expressando um modo de pensamento do ocidente (HEIDEGGER, 2005). Com isso, de acordo com o autor, precisamos dar um passo atrás, no sentido de encontrar a essência da técnica, que não tem nada de técnico. Ao consideramos a técnica neutra, imaginamos dominá-la de acordo com nossos interesses, acabamos completamente cegos em relação à essência da técnica. A intenção desse artigo é trazer à luz a concepção de Heidegger acerca da questão da técnica, com o objetivo de contribuir com as discussões que permeiam a escola, em relação a incorporação das TD. Então, questionaremos a técnica para construção de um caminho, pois "todo o caminho é uma construção do pensamento" (HEIDEGGER, 2012, p. 12) e entendemos que por essa via, conseguimos entender a essência da técnica e evitar uma declaração de amor apressada à tecnologia.

\section{ONDE MORA O PERIGO, TAMBÉM CRESCE O QUE SALVA ${ }^{2}$}

Heidegger (2012) conceitua a técnica moderna de duas formas: a) é uma atividade humana e b) é um meio para alcançar determinados fins. Por isso, entende que se trata de uma concepção instrumental e antropológica da técnica. De acordo com essa concepção, manipulamos a técnica de acordo com nossas habilidades e que o domínio da tecnologia pertence unicamente ao sujeito. Concordamos com o filósofo de que a concepção instrumental e antropológica da técnica é correta, mas apenas essa concepção não contribui para descobrir a essência da técnica, que não tem nada de técnico.

\footnotetext{
${ }^{1}$ Movimento que surgiu em 1811 e 1812 na Inglaterra, que defendia a destruição das máquinas.

${ }^{2}$ Esse subtítulo foi inspirado no poema de Hölderlin, citado por Heidegger no texto "A questão da técnica".
}

DIALEKTIKÉ, v. 1, novembro 2014, p. 17-28

Artigo submetido em agosto/2014 e aceito em outubro/2014 
Precisamos, de acordo com o filósofo, perguntar acerca do "que é o instrumental em si mesmo? A que pertence meio e fim?” (HEIDEGGER, 2012, p. 13). Ele mesmo responde que: "onde se perseguem fins, aplicam-se meios, onde reina a instrumentalidade, também impera a causalidade" (idem), assim se faz necessário examinar a causalidade.

Heidegger expõe as quatro causas aristotélicas para compreender o fundamento unificador que as qualifica como causa: 1) a causa materialis, o material para a produção de um artefato; 2) a causa formalis, a forma - a figura em que se insere o material; 3) a causa finalis, a finalidade; 4) a causa efficiens, o operário que produz o efeito, o artefato pronto. Assim, conforme Heidegger (2012, p. 13), “descobre-se a técnica concebida como meio, reconduzindo-se a instrumentalidade às quatro causas".

De alguma forma, atribuímos toda a causalidade a causa efficiens, pois "costuma-se conceber a causa como o que é eficiente. Ser eficiente significa, aqui, alcançar, obter resultados e efeitos”. (p.13-14) Acabamos reduzindo o sentido de produção apenas a atividade do homem e reproduzimos a concepção antropológica instrumental da técnica, como abordado no início desse artigo. Heidegger salienta que essa concepção de eficiência não existia para os gregos, e sim a ideia de responder $e$ dever à outra coisa. Como no exemplo fornecido pelo filósofo, na produção do cálice de prata. $\mathrm{O}$ cálice responde ou deve, à prata. A causa efficiens, a reflexão do operário para a produção do artefato é apenas uma das causas, mas não a única. Em outras palavras, as quatro causas de responder e dever levam alguma coisa a aparecer, ou conforme Heidegger (2012, p. 15), "deixam que algo venha a viger, a saber, em seu pleno advento. No sentido deste deixar, responder e dever são um deixar-viger" e complementa com uma citação de Platão que "todo deixar-viger o que passa e procede do não vigente para a vigência é pro-dução". Nas palavras de Heidegger a pro-dução conduz do encobrimento para o desencobrimento, que "os gregos possuíam a palavra $\dot{\alpha} \lambda \eta ́ \vartheta \varepsilon 1 \alpha$. Os romanos veritas e nós dizemos 'verdade' e a entendemos geralmente como o correto de uma representação" (2012, p. 16). Dessa forma,

A técnica não é, portanto, um simples meio. A técnica é uma forma de desencobrimento. Levando isso em conta, abre-se diante de nós todo um outro âmbito para a essência da técnica. Trata-se do âmbito do desencobrimento, isto é, da verdade. (HEIDEGGER, 2012, p. 17)

DIALEKTIKÉ, v. 1, novembro 2014, p. 17-28

Artigo submetido em agosto/2014 e aceito em outubro/2014 
Heidegger destaca que essa afirmação nos causa estranheza e o deve fazer, pois assim levamos a sério e questionamos o que nos diz a palavra "técnica", que distancia-se da ideia que é um meio para atingir determinados fins para a verdade. Ainda ressalta que devemos considerar duas coisas em relação ao sentido dessa palavra. De um lado, a

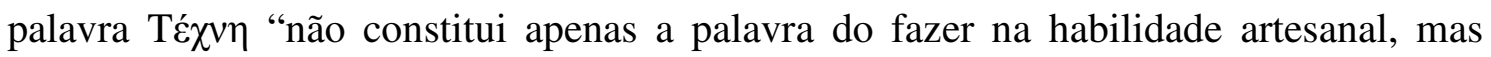
também do fazer da grande arte" (HEIDEGGER, 2012, p. 17). De outro lado, a palavra Té $\chi \vee \eta$

\begin{abstract}
Des-encobre o que não se produz a si mesmo e ainda não se dá e propõe, podendo assim apresentar-se e sair, ora num, ora em outro perfil. Quem constrói uma casa ou um navio, quem funde um cálice sacrificial des-encobre o ser produzido nas perspectivas dos quatro modos de deixar-viger. Este des-encobrir recolhe antecipadamente numa unidade o perfil e a matéria do navio e da casa numa coisa pronta e acabada e determina dai o modo da elaboração. O decisivo da

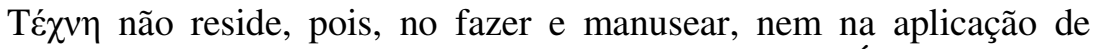
meios, mas no desencobrimento mencionado. É neste des-

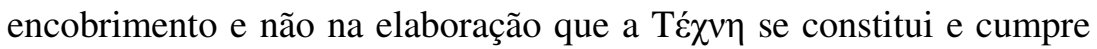
uma pro-dução. (HEIDEGGER, 2012, p. 17-18)
\end{abstract}

Assim, a Té $\chi v \eta$ não possuía um sentido fechado, fixo, que demarcava constantemente o des-encobrir. "A arte chama-se apenas TÉ $\chi \vee \eta$. Era um des-encobrir-se único numa multiplicidade de desdobramentos" (HEIDEGGER, 2012, p. 36), que a cada pro-dução criava um novo perfil, entre diversos caminhos possíveis.

Nesse ponto, refazemos a pergunta que iniciou esse tópico: qual é a essência da

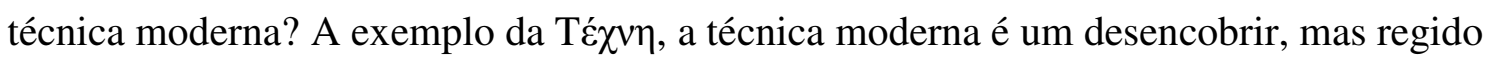
pela interpelação provocadora e não por um pro-duzir no sentido grego. Justamente ai

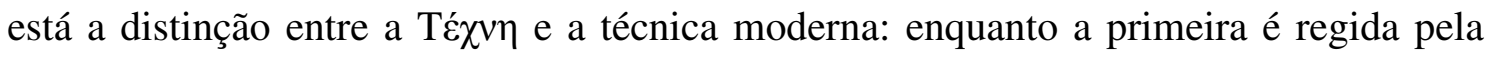
liberdade de pro-dução, a segunda "possui como característica, o pôr, no sentido de explorar" (HEIDEGGER, 2012, p. 20), de dis-ponibilizar. A exploração é o que leva os homens a considerar o real como recurso, "um processo baseado no cálculo do ente" (RUDIGER, 2006, p. 136).

Regidos pelo pensamento calculador, se destrói florestas para criar novas pastagens para o gado ou para monoculturas; se esteriliza a semente nativa e através da biotecnologia cria a semente estéril controlada pelas grandes corporações. Em outras palavras, o capital se apropria da técnica, transformando tudo em matéria-prima, em 
recursos, inclusive o próprio homem. Assim, pela técnica moderna é "descerrada a energia oculta na natureza, o que se descerra é transformado, o que se transforma é reforçado, o que se reforça é armazenado, o que se armazena é distribuído" (HEIDEGGER, 2002, p.195). Nessa concepção, pela educação, estaríamos sempre procurando aprender o que é útil e atual para o mercado para nos tornarmos mais habilidosos, ou seja, nos mostrar como recurso, como os objetos que nos cercam.

Diante disso, "este querer dominar torna-se tanto mais urgente quanto mais a técnica ameaça a escapar do controle do homem" (HEIDEGGER, 2012, p.12). Eis a essência da técnica moderna, a interpelação provocadora: exigir que o homem se torne senhor da técnica. Trata-se de um processo de objetivação do mundo e que, ao mesmo tempo, transforma o homem em subjetum, o homem está por traz de tudo, capaz ele mesmo de gerar o objeto, o mundo é transformado em imagem do mundo (HEIDEGGER, 2005).

Reinhart Maurer em seus estudos acerca do nazismo e a técnica, afirma que Heidegger já havia discernido que: "o nazismo almejava uma harmonia entre o homem e a técnica. Uma nova humanidade, uma espécie de super-homem"(1999, p.404) e mesmo com a destruição do nazismo, "outras vontades de poder coletivas prosseguem, de modo intensificado, numa direção semelhante" (p.405) e deveríamos levar em conta o que Heidegger aprendeu com o nazismo: "que se encontra por princípio fracassado o anseio por uma humanidade a ser recriada pela vontade de poder tecnologicamente mediada" (MAURER, 1999, p.410). Um exemplo dessa vontade de poder esteve nas manchetes do mundo, quando Edward Snowden denunciou o monitoramento em massa ${ }^{3}$ que a Agencia Nacional de Segurança (NSA) dos Estados Unidos realiza. Denúncia que traz à luz uma cyber-guerra, que nada mais é do que vontade de poder mediado pela técnica.

Entretanto, de acordo com Heidegger, essa vontade de poder é o que nos faz agir de acordo com o pensamento calculador, pois

O dilema do senhor e do escravo não atinge o âmbito da situação que aqui impera. Quando tiver tido sucesso o controle da energia atômica, significa isto já que o homem se tornou senhor da técnica? De modo algum. A necessidade do controle atesta justamente o poder da

\footnotetext{
${ }^{3}$ Realizado pelo PRISM, um programa de monitoramento em tempo real da circulação de informações na internet.
}

DIALEKTIKÉ, v. 1, novembro 2014, p. 17-28

Artigo submetido em agosto/2014 e aceito em outubro/2014 
interpelação produtora, revela o reconhecimento desse poder, trai a impotência do agir humano para dominá-lo, mas contém, ao mesmo tempo, um aceno para, mediante a reflexão nos inserirmos no mistério ainda velado do poder da interpelação produtora. (HEIDEGGER, 2002, p. 202)

Desse modo, cria-se uma civilização planetária regida pela técnica, pois o esforço em dominá-la ou acabar com ela não são sinais de humanidade, mas justamente o contrário, demonstração do poderio da interpelação provocadora. De acordo com o filósofo, nossa forma de pensar e agir é interpelada pela técnica, ou seja, "o homem está posto sob a ameaça crescente de perder sua humanidade" (HEIDEGGER, 2002, p. 197), o que significa, o esquecimento do ser. Assim, "quanto mais nos avizinharmos do perigo, com maior clareza começarão a brilhar os caminhos para o que salva" (HEIDEGGER, 2012, p. 38). No perigo de encerrar o homem em uma única forma de desencobrimento é que questionamos a técnica para que o caminho do pensamento seja construído com liberdade e que a técnica seja apenas um dos caminhos para tal e não "o caminho" como os tecnófilos costumam pregar.

\section{UM SALTO PARA FORA DO OLHO DO FURACÃO}

Segundo Giovanni Sartori, atualmente, vivemos um processo de metamorfose em que o vídeo está transformando o Homo Sapiens em Homo Videns. Segundo o autor, a palavra vem sendo destronada pela imagem. Antes mesmo de aprender a ler e escrever, as crianças assistem televisão, o que faz com que predomine o visível (imagem) sobre o inteligível (conceitos), que conduz para um ver sem entender. Conforme Sartori (2001), o homo sapiens é único pela sua capacidade simbólica, que se desdobra na linguagem, isto é, o homem é um animal que fala e que pode refletir sobre o que diz. Na televisão o falar é secundário, basta ver a imagem e pronto. Com isso, enfraquece nossa disposição em refletir e acabamos reforçando a interpelação produtora, pois no dia-a-dia entramos em uma lógica da velocidade que dificilmente paramos para dialogar com o colega; nas reuniões sempre cobramos objetividade, tratase do pensamento calculador operando sobre nossas vidas. Nesse caso, o mero uso de objetos tecnológicos, sem nenhuma reflexão pode levar a constituição de uma ignorância profunda.

DIALEKTIKÉ, v. 1, novembro 2014, p. 17-28

Artigo submetido em agosto/2014 e aceito em outubro/2014 
Diante disso, entendemos que a função primeira da escola seja promover um "parar para pensar", no sentido de privilegiar a reflexão e o diálogo. Trata-se de construir um caminho do pensamento com liberdade, no sentido que Vattimo (2002) denominou de loisir, ou "jogo", que é o "partilhar, já sempre dado com a nossa existência histórica, de um horizonte no qual a experiência dos fenômenos e o conhecer científico nos tornam possíveis" (VATTIMO, 2002, p. 36). Não se trata de compartilhar algo dado como no mundo das ideias (faço referência a "alegoria da caverna" de Platão) em que as coisas são perfeitas e servem como matriz para o mundo das coisas sensíveis. Mas, socializar um conhecimento que não está presente fora da escola, a ciência da computação ${ }^{4}$. Não se trata de fazer com que todos conheçam o funcionamento da máquina, mas que tenham um olhar para o mundo com essa nova ótica, para que não sejam cooptados por um pensamento calculador, que apenas nos empurra para dentro do olho do furacão do consumo e dis-ponibiliza tudo e todos como recurso.

Nesse sentido, a tradição é o único parâmetro que possuímos. Então, de acordo com Arendt (1992) o novo (a criança) que chega ao mundo precisa ser protegida do mundo e o mundo precisa ser protegido do novo, a fim de garantir sua conservação. Assim, "exatamente em benefício daquilo que é novo e revolucionário em que a criança é que a educação precisa ser conservadora" (ARENDT, 1992, p.243). Em outras palavras, as gerações mais velhas têm a responsabilidade na educação das novas gerações (DALBOSCO, 2011).

Nesse sentido, um permanente diálogo entre gerações se faz necessário para que ambas se transformem, pois caso a tradição fosse sempre repetida, cada nova geração seria uma cópia exata da anterior, porém “o homem não mantém com a tradição relação unicamente passiva, mas também interativa. Ao recuperá-la, ele a recria, recriando-se também" (WADDINGTON, 2002, p. 182). O que nos coloca em uma situação de permanente diálogo com o outro e com a tradição. Portanto, a tradição e a interpretação assim como o jogo são expressões de liberdade e abertura do ente ao ser.

Através de uma metáfora, narrada por Arendt, que versa acerca de uma visita de Ulisses à corte dos Feaces e,

\footnotetext{
${ }^{4}$ Nesse caso, merece uma distinção entre informática e Ciência da Computação. Informática trata-se de operação de computadores: editores de texto, de slides, softwares aplicativos e automatização de empresas. Ciência da Computação trata-se de um conhecimento acerca de teorias, métodos, linguagens e modelos computacionais. Existem várias escolas desenvolvendo esse tipo de trabalho, utilizando como referência o livro Computer Science Unplugged -Ensinando ciência da computação sem computadores.
}

DIALEKTIKÉ, v. 1, novembro 2014, p. 17-28

Artigo submetido em agosto/2014 e aceito em outubro/2014 
Por ordem do rei, é divertido pelo bardo, que conta uma história qualquer da vida do próprio Ulisses, a sua disputa com Aquiles: Ulisses, ouvindo, cobre a face e chora, embora nunca tenha chorado antes, e certamente não quando o que agora está a ouvir aconteceu realmente. Só quando ouve a história é que fica completamente cônscio do seu sentido. (ARENDT, 1977, p. 150)

A autora ilustra a importância da linguagem para a construção do sentido. Nas palavras do filósofo alemão: "no pensamento do sentido, chegamos propriamente onde, de há muito, já nos encontramos, embora sem tê-lo experienciado e percebido" (HEIDEGGER, 2012, p. 58). Com isso, percebemos a necessidade do permanente diálogo nas instituições educacionais para que ocorra uma construção de sentido para o uso das tecnologias interativas na educação. Então, percebemos que a fala é necessária para a própria elaboração dos pensamentos. Conforme Heidegger (1983), a linguagem é morada do ser e o homem pastor do ser. Em outras palavras, o ser é o possível do mundo e de nós mesmos, mas entregue aos nossos cuidados e sob nossa responsabilidade. Conforme Schneider (2005), o ser "não é constituído pelo pensamento, nem dele é originado ou mesmo realizado. Ao invés disso, o ser revela-se no pensar" (p.15). Heidegger assim propõe uma nova forma de pensar em que a linguagem tem papel fundamental. Desse modo,

possuímos razões para crer que o pensamento e a palavra são originalmente poéticos, criadores de mundo e, portanto, doadores de sentido à existência. Nesse sentido, o pensamento representa um elemento que, enquanto existir, será sempre uma espécie de limite extremo ao, senão um meio de dar eventual contra-golpe no universo maquinistico. (RUDIGER, 2006, p. 197)

Não se trata de destruir a técnica, mas construir uma relação livre com ela, de forma que a técnica não se aproprie de nosso pensamento, fazendo com que acreditemos mais na tecnologia do que nas outras pessoas. Para isso, questionamos a técnica, pois "pensar inclui questionar [...], uma resposta nos impele para outras questões: 'filosofar é filosofar', não um corpo de verdades" (INWOOD, 2002, p. 143). Em outras palavras, ao 
questionar a técnica provocamos a abertura do ser, um filosofar sempre que é a essência do Das-ein.

\section{CONCLUSÃO}

Nossa intenção ao expor a questão da técnica em Heidegger foi criar uma provocação e um convite para pensarmos acerca da técnica. A concepção instrumental e antropológica é uma concepção predominante na escola: um instrumento, um meio para alcançar determinados fins. Conforme Heidegger essa concepção é correta, mas faz com que não percebemos a essência da técnica e acaba prevalecendo a interpelação provocadora. Acabamos caindo na armadilha do uso da tecnologia pela tecnologia, sem uma interação crítica-reflexiva para construção de um sentido. Assim, negamos a possibilidade de democratizar um conhecimento que está acessível apenas para alguns: o conhecimento da ciência da computação. Trata-se de preparar um caminho não para a técnica, mas para a essência da técnica. Nesse caso, o papel da escola, é socializar esse conhecimento e orientar as novas gerações para construir um senso crítico e discernir quando e porque empregar determinadas tecnologias.

Portanto, precisamos criar na escola um momento do "parar para pensar" no lugar do apenas valorizar o fazer utilitarista. No sentido de privilegiar o diálogo e o pensamento, pois no dia-a-dia entramos em uma lógica da velocidade que dificilmente paramos para dialogar com o colega; nas reuniões sempre cobramos objetividade, tratase do pensamento calculador operando em nossas vidas. Imaginar que a tecnologia nos confere um poder especial que resolva todos nossos problemas é no mínimo ingenuidade, é colocar na tecnologia o poder divino, com a esperança de chegar a todas as respostas, como na idade média. O que aprendemos, construímos e vivenciamos pode ser reconstruído pelo diálogo com os outros tendo como base a tradição, a finitude. Não foi por acaso que Heidegger afirmou que a linguagem é a morada do ser. A linguagem joga alguma luz em nossas compreensões da vida, é mais do que um instrumento de comunicação, ela nos constitui enquanto seres humanos. Pela linguagem nós inventamos e reinventamos as nossas vidas.

\section{REFERÊNCIAS}

DIALEKTIKÉ, v. 1, novembro 2014, p. 17-28

Artigo submetido em agosto/2014 e aceito em outubro/2014 
ARENDT, H. (1977): A vida do espírito. Lisboa: Instituto Piaget.

(1992): Entre o passado e o futuro. 3. Ed. São Paulo: Perspectiva.

CAMBRAIA, A. C. (2013): Domínio e Cultura Informática na Escola. Revista

Linhas. Florianópolis: v. 14 n. 27. Jul. / Dez. 2013. p. 105 - 133. Acessado no endereço: <http://dx.doi.org/10.5965/1984723814272013105>

DALBOSCO, C. A. (2011): Educação natural em Rousseau: das necessidades da criança e dos cuidados do adulto. São Paulo: Editora Cortez.

FARIAS, L. C.; DIAS, R. E. (2013): Discursos sobre o uso das TIC na educação em documentos Ibero-americanos. Revista Linhas. Florianópolis: v. 14 n. 27. Jul. / Dez. 2013. P. 83 - 104. <Acessado no endereço: http://dx.doi.org/10.5965/198472381427201383>

HEIDEGGER, M. (1983): Conferências e escritos filosóficos. Traduzido por: Ernildo Stein. São Paulo: Abril Cultural.

(2002): O enigma da sociedade industrial (carta-resposta Revista Begegnung, 1965). In: STEIN, E. Uma breve introdução à filosofia. Ijuí: Ed. Unijuí, 2002.

(2005): A época da imagem do mundo. In: SCHNEIDER, Paulo Rudi. O outro pensar: sobre que significa pensar? E a época da imagem do mundo, de Heidegger. Ijuí: Ed. Unijuí.

(2012): Ensaios e Conferências. Traduzido por: Emmanuel Carneiro Leão, Gilvan Fogel, Marcia Sá Cavalcante Schuback. 8.ed. Petrópolis: Vozes; Bragança Paulista: Editora Universitária São Francisco.

MAURER, R. (1999): O que existe de propriamente escandaloso na filosofia da técnica de Heidegger. Revista internacional de filosofia e práticas psicoterápicas. Grupo de Pesquisa em Filosofia e Práticas Psicoterápicas do Programa de Estudos PósGraduados em Psicologia Clínica da PUC-SP.vol. 1, n 1(1999). São Paulo: Educ.

RÜDIGER, F. (2006): Martin Heidegger e a questão da técnica: prospectos acerca do futuro do homem. Porto Alegre: Sulina.

SARTORI, G. (2001): Homo videns: televisão e pós-pensamento. Traduzido por: Antônio Angonese. Bauru, SP: EDUSC.

SCHNEIDER, P. R. (2005): O outro pensar: sobre o que significa pensar? e a época da imagem do mundo, de Heidegger. Ijuí: UNIJUI.

TURKLE, S. (2011): Alone Together. New York: Basic Books. 
VATTIMO, G. (2002): Sociedade do conhecimento ou sociedade loisir? Revista tempo Brasileiro, jan.-mar- n. 148. Rio de Janeiro: Tempo Brasileiro Ed.

WADDINGTON, C. B. G. (2002): Tradição, conhecimento e interpretação. Revista Tempo Brasileiro, jan.-mar- n. 148. Rio de Janeiro: Tempo Brasileiro Ed. 